\title{
Investigating the prevalence of antibiotics prescription in the toxicology ward of a referral hospital in the North of Iran
}

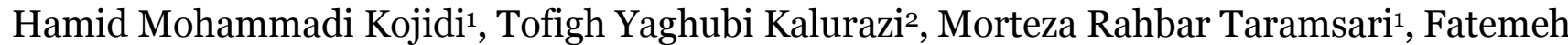 \\ Daneshsefatdoost ${ }^{1}$, Alireza Badsar ${ }^{1}$, Paria Okhovat ${ }^{2}$, Mirsaeed Attarchi, ${ }^{1,2}{ }^{*}$ \\ ${ }^{1}$ Department of Forensic Medicine, School of Medicine, Guilan University of Medical Sciences, Rasht, Iran \\ ${ }^{2}$ Razi Clinical Research Development Unit, Razi Hospital, Guilan University of Medical Sciences, Rasht, Iran
}

\begin{abstract}
Antibiotic resistance of microorganisms is a serious problem in medicine. One of the most common reasons for this issue is the improper prescription of antibiotics by physicians. The purpose of the study was to investigate the prevalence of using antibiotics in the toxicology ward of Razi Hospital. In this retrospective descriptive cross-sectional study, 338 patients admitted to the toxicology ward of Razi hospital were enrolled from March 2018 until March 2019. A checklist of investigated factors including age, gender, fever, paraclinical findings, type of poisoning, and type of antibiotic prescribed was completed for all patients. About $52.1 \%$ of the participants were males and $47.9 \%$ were females. The mean age of participants was $37.07 \pm 17.36$ years. Antibiotics had been prescribed for 49 patients. The most common form of poisoning was benzodiazepines. Also, ceftriaxone was the most common antibiotic prescribed to the patients. Fever existed in $69.4 \%$ of the patients receiving antibiotics. The most common paraclinical finding was abnormal complete blood count (CBC) in patients (leukocytosis) which was seen in $83.7 \%$ of them. The antibiotics mostly had been prescribed in the first two days of hospitalization. In the present study, antibiotics were prescribed in the toxicology ward for only $14.5 \%$ of the poisoned patients. Considering that ceftriaxone has been the most commonly prescribed antibiotic, its use has to be based on clinical evidence based on the necessary indications according to scientifically substantiated sources.
\end{abstract}

Keywords: Drug use, Antibiotics, Toxicology ward

\section{Introduction}

The introduction and use of antibiotics have led to a great revolution in the treatment of infectious diseases such that the epidemiological pattern of diseases changed from infectious to non-infectious and accidents [1,2]. Afteranalgesics, antibiotics are the second most widely used drugs and their use has shown an upward trend over the years [3, 4]. Concerns about using antibiotics became known shortly after their introduction to the medical world [5]. Using new antibiotics in the following decades was accompanied

\section{"Corresponding author:}

Mirsaeed Attarchi, MD

Department of Forensic Medicine, School of Medicine,

Guilan University of Medical Sciences, Rasht, Iran

Tel/Fax: +98 1333690006

Email: : msattarchi@yahoo.com

https://orcid.org/oooo-0002-7730-688X

Received: May, 07, 2021

Accepted: July, 19, 2021 by an irrational increase in their use, leading to the emergence of nosocomial infections and emerging infections $[6,7]$.

Antibiotic resistance in microorganisms is one of the serious problems in infectious medicine, the main reason is the improper prescription of antibiotics by physicians. The research has shown that at least onethird of the hospitalized patients receive a course of antibiotics, and almost half of these antibiotics are prescribed unnecessarily or incorrectly $[8,9]$. Even though antibiotics are required in most bacterial
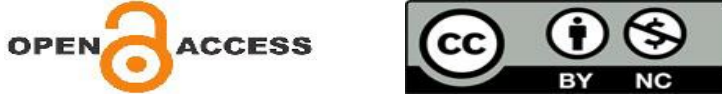
infections and do not pose a threat to the patient's life, most studies have shown that 30 to $60 \%$ of cases are inappropriate [10].

The global cost of antibiotics in 2005 was estimated at $\$ 40$ billion, of which developing countries accounted for about one-third [11]. According to a world health organization (WHO) report based on data collected from 65 countries in 2015, amoxicillin and amoxicillin-clavulanate were the most widely used antibiotics [12]. As there are few studies on the pattern of antibiotic administration in Iran, the present study was conducted to investigate the frequency of antibiotic prescribing in the toxicology ward of a referral hospital in the North of Iran.

\section{Materials and Methods}

\subsection{Design and the population}

The population of this study included the patients admitted to the toxicology ward of Razi Hospital in 2018. In this cross-sectional descriptive study, the files of 338 patients in the toxicology ward of Razi hospital were selected using regular systematic random sampling. Then, they were investigated over one year from April 2018 to March 2019 and the number of patients being prescribed at least one antibiotic during this time was recorded. Razi Hospital in Rasht is the main referral center for patients suffering from toxication, in Gilan Province, North of Iran. For each patient, demographic information and the type of antibiotic prescribed were collected from the file. In this study, fever was reported to be above $37.2^{\circ} \mathrm{C}$ in the morning and above $37.7^{\circ} \mathrm{C}$ in the evening by the oral method. Abnormal complete blood count (CBC) was considered leukocytosis (WBC> 11000) in the study. The study design was approved by the regional ethic committee of Guilan University of Medical Sciences with the approval code of IR.GUMS.REC.1399.051. Information was collected and recorded from patients' files anonymously and in complete confidentiality. The researchers of the project adhered to the code of ethics in all stages of the study.

\subsection{Statistical analysis}

The collected data were entered into SPSS ver.22 and were analyzed. The results were presented as frequency and percentage. Chi-square or Fisher's exact tests was used to estimate any statistical association for quantitative variables, and paired t- tests were used to compare means. A p $<0.05$ was regarded as significant relevance.

\section{Results}

In this study, the files of 338 patients were examined from April 2018 until March 2019. Among these patients, 176 patients (52.1\%) were males and 162 patients (47.9\%) were females. The mean age of the entire patient was $37.07 \pm 17.36$ years. The mean age of the patients prescribed antibiotics (44.83 \pm 18.97 years) was significantly higher than patients not prescribed antibiotics $(35.93 \pm 16.73$ years $)(p<0.05)$. Moreover, 170 (50.3\%) patients were in the age group 20-40 years, 67 (19.8\%) and 55 (16.3\%) in 40-60 years and less than 20 years, and $46(13.6 \%)$ were in the group over 60 years. Of the 338 patients, antibiotics were prescribed for 49 patients (14.5\%).

Table 1 presents the distribution of the frequency of poisoning agents and the frequency of antibiotic administration according to the toxicology ward. As can be seen from the table, the highest frequency of poisoning is related to benzodiazepines. The highest frequency of antibiotic use was in multidrug poisoning (24.5\%), followed by methadone (22.4\%). Of the 49 patients to whom antibiotics were prescribed, $63.3 \%$ (31 people) were males and $36.7 \%$ (18 people) were females. Overall, the frequency of antibiotics was higher for men compared to women so that $17.6 \%$ of male patients and $11.1 \%$ of female patients were prescribed antibiotics. As specified in Table 2, the highest prevalence of antibiotics was in people over 60 years of age so that 46 of the poisoned people were over 60 years of age. Table 2 shows the frequency of antibiotic prescribing by age group and hospitalization days. Of the 49 patients to whom antibiotics were prescribed, 21 were in the age group of 20-40 years and the highest frequency of antibiotic administration was with 21 cases on the first day of hospitalization (Table 2).

Table 3 presents the frequency distribution of different types of prescribed antibiotics. As can be seen, ceftriaxone was the most commonly used antibiotic with 41 cases. Moreover, it is the most common antibiotic used in both genders and all age groups. Table 4 presents the clinical and paraclinical findings regarding the cases in which antibiotics were prescribed. Abnormal fever and whole blood test (leukocytosis) were seen in $69.4 \%$ and $57.1 \%$ of patients receiving antibiotics, respectively. In 9 cases 
for whom antibiotics were prescribed, fever and abnormal paraclinical findings did not exist and antibiotics were used based on the patient's complaints and symptoms or for prophylaxis. files of patients admitted to the toxicology ward of an educational and medical center. In the current study, of 338 patients investigated, the highest number of poisoned patients was in the age range of 20-40 years.

Table 1. The frequency of poisoning agent and antibiotic prescription according to poisoning factor

\begin{tabular}{ccccc}
\multirow{2}{*}{ Cause of poisoning } & \multicolumn{2}{c}{ Poisoning } & Antibiotic prescription \\
\cline { 2 - 5 } & Frequency & Percentage & Frequency & Percentage \\
\hline Benzodiazepine & 74 & 21.9 & 5 & 10.2 \\
\hline Aluminum phosphide & 28 & 8.3 & 2 & 4.1 \\
\hline Methadone & 29 & 8.6 & 11 & 22.4 \\
\hline Metformin and Glibenclamide & 3 & 0.9 & 0 & 0 \\
\hline Opium & 23 & 6.8 & 4 & 8.2 \\
\hline Snake and spider bites & 5 & 1.5 & 3 & 6.1 \\
\hline Rat poison & 3 & 0.9 & 0 & 0 \\
\hline Alcohol & 17 & 5 & 0 & 0 \\
\hline Cannabis and amphetamines & 5 & 1.5 & 1 & 2 \\
\hline Tramadol & 16 & 4.7 & 2 & 4.1 \\
\hline Propranolol & 1 & 0.3 & 0 & 0 \\
\hline Acetaminophen and NSAIDs & 12 & 3.6 & 0 & 0 \\
\hline Hydrogen chloride & 2 & 0.6 & 0 & 0 \\
\hline Diesel and hydrocarbons & 2 & 0.6 & 1 & 2 \\
\hline Expectorant and rasperidone & 3 & 0.9 & 1 & 2 \\
\hline Carbon monoxide & 2 & 0.6 & 1 & 2 \\
\hline Pepsinogen inhibitor & 1 & 0.3 & 0 & 0 \\
\hline Barbiturates and antiepileptics & 2 & 0.6 & 1 & 2 \\
\hline Mushrooms & 6 & 1.8 & 2 & 4.1 \\
\hline Lead and arsenic & 2 & 0.6 & 1 & 2 \\
\hline Insecticides and herbicides & 19 & 5.6 & 0 & 0 \\
\hline SSRI and TCA & 4 & 1.2 & 1 & 2 \\
\hline Bleach & 6 & 1.8 & 0 & 0 \\
\hline Botulism & 8 & 2.4 & 0 & 0 \\
\hline Multi-drug & 47 & 13.9 & 12 & 24.5 \\
\hline Unknown & 18 & 5.3 & 1 & 2 \\
\hline Total & 338 & 100 & 49 & 100 \\
\hline & & & & \\
\hline & & & & 0 \\
\hline
\end{tabular}

Abbreviations: NSAIDs, Nonsteroidal anti-inflammatory drugs; SSRIs, Selective serotonin reuptake inhibitors; TCA, Tricyclic antidepressants

\section{Discussion}

Irrational use of antibiotics in hospitalized patients is a critical issue in medical and environmental studies. Unnecessary use of antibiotics, inadequate monitoring, inappropriate dosing, and administration of multiple antibiotics are examples of cases of inappropriate use of antibiotics in hospital settings. These cases can increase the prevalence of antibiotic-resistant strains and lead to prolonged hospitalization, side effects, and loss of medical budget [13-15]. In this cross-sectional study, the prevalence of antibiotics in patients was investigated by studying the
The most common type of poisoning was benzodiazepines. Overall, antibiotics were prescribed in $14.5 \%$ of patients admitted to the toxicology ward, which is less common compared to similar internal and external studies performed in other hospital wards.

The history of chronic disease has a key role in the physician's decision for prescribing antibiotics and most of the patients hospitalized in the toxicology ward were young and in the age range 20-40 years with no underlying disease. Therefore, this factor can be considered as the hypothesis of the reasons for the 
Table 2. Frequency of antibiotic prescription by the time of administration and age group

\begin{tabular}{|lcc|}
\hline Variable & Frequency & Percentage \\
\hline $\begin{array}{l}\text { Antibiotic time } \\
\text { (day of hospitalization) }\end{array}$ & & \\
\hline First & 21 & 42.9 \\
\hline Second & 20 & 40.8 \\
\hline Third & 6 & 12.2 \\
\hline Fourth & 0 & 0 \\
\hline Fifth & 2 & 4.1 \\
\hline Age groups (years) & & \\
\hline Under 20 & 4 & 8.2 \\
\hline 20 to 40 & 21 & 42.8 \\
\hline 41 to 60 & 14 & 28.6 \\
\hline Over 60 & 10 & 20.4 \\
\hline Total & 49 & 100 \\
\hline
\end{tabular}

Table 3. The frequency of various types of prescribed antibiotics

\begin{tabular}{lcc}
\hline Types of antibiotic & Frequency & Percentage \\
\hline Ceftriaxone & 41 & 12.1 \\
\hline Clindamycin & 17 & 5 \\
\hline Meropenem & 5 & 1.5 \\
\hline Vancomycin & 5 & 1.5 \\
\hline Cefazolin & 3 & 0.9 \\
\hline Metronidazole & 2 & 0.6 \\
\hline Levofloxacin & 2 & 0.6 \\
\hline Penicillin & 2 & 0.6 \\
\hline Ciprofloxacin & 2 & 0.6 \\
\hline Imipenem & 1 & 0.3 \\
\hline Cephalexin & 1 & 0.3 \\
\hline Piperacillin & 1 & 0.3 \\
\hline Azithromycin & 1 & 0.3 \\
\hline Ceftazidime & 1 & 0.3 \\
\hline
\end{tabular}

Table 4. Frequency of abnormal clinical and paraclinical finding in patients receiving antibiotics

\begin{tabular}{lcc}
\hline Abnormal finding & Frequency & Percentage \\
\hline Complete blood test & 28 & 57.1 \\
\hline Chest X-ray & 11 & 22.4 \\
\hline $\begin{array}{l}\text { Complete urine test } \\
\text { or urine culture }\end{array}$ & 4 & 8.2 \\
\hline Fever & 34 & 69.4 \\
\hline
\end{tabular}

low prevalence of antibiotics in this ward. Ceftriaxone was the most commonly prescribed antibiotic in both genders. In a study by Gholami et al., 190 patients receiving antibiotics in the emergency ward of a teaching hospital in Tehran were examined for the accuracy of the indication, the type of antibiotic, dose, and method of administration. In their study, ceftriaxone was the most commonly prescribed antibiotic with $72.1 \%$, while $36.3 \%$ of the prescribed antibiotics being inappropriate, and in $15.8 \%$ of the cases, antibiotics prescription was unnecessary. Overall, considering mistakes in the diagnosis, indication, type of antibiotic, dose, and method of drug administration, 77 mistakes were made in the antibiotics prescription [16]. Ebrahimzadeh et al. examined antibiotic use patterns in several hospital wards in Sari from 2000 to 2005 using ATC/DDD method. The use of antibiotics from April 2000 for six months was 95.4 units and from April 2005 for six months was 124 units. This was obtained by dividing the specified daily value by the number of occupied beds, multiplied by the number of days, multiplied by 100 (DDD/10obed-day). Cefazolin was the most widely used drug of all time. Intensive care unit (ICU) and obstetrics wards had the highest dose of antibiotics from March to August 2005. Over time, the largest increases were related to vancomycin and clindamycin [17]. In a study by Robert et al., the spot prevalence of antibiotic use was evaluated in a volunteer sample from French hospitals. Among 3,964 patients in 38 hospitals, 343 (8.7\%) patients used antimicrobial prophylaxis and 1276 (32.2\%) antimicrobial therapy. Among patients receiving antimicrobial therapy, 959 (75.2\%) patients received beta-lactam, 34.8\% penicillin beta-lactam inhibitor, 22.1\% third-generation cephalosporins, and $7.8 \%$ carbapenems. In aggregate, 518 (40.6\%) patients received more than one antibiotic [18].

In the present study, the most prevalent paraclinical result in patients receiving antibiotics was leukocytosis. Blood culture was carried out in only 2 cases that were reported negatively. Fever existed in $69.4 \%$. Of the 49 patients receiving antibiotics, 9 had neither abnormal paraclinical findings nor fever, and antibiotics were administered just according to the patient's symptoms and complaints or for prophylaxis. In our study, in line with other studies from Iran, cephalosporins were the most commonly used antibiotic. Out of the 49 patients to whom antibiotics were prescribed, $83.7 \%$ were prescribed antibiotics in the first two days of hospitalization. Therefore, antibiotics are unlikely in most cases due to 
nosocomial infections. One of the limitations of this study was that it is retrospective, leading to some problems in obtaining information. Therefore, it is recommended to conduct a more comprehensive study with a larger sample size. Moreover, a prospective study with a more detailed checklist is needed to conduct in other teaching hospitals in this province.

Improper prescription of antibiotics can affect the whole society by creating resistant strains. Moreover, one of the reasons for over-prescribing antibiotics is doctors' lack of knowledge about the indications for prescribing antibiotics. Hence, it seems that codified teaching and emphasis on how to prescribe properly these drugs can be very effective. Currently, in the modern hospitals of the world, different measures like training programs, the use of antibiotic prescription forms, clinical guides of prescribing antibiotics, and direct or telephone consultation with infectious disease specialists are performed to limit the prescription of antibiotics to prevent the overprescription of antibiotics, thereby reducing the hospital costs and the emergence of resistant species [19].

In the present study, antibiotics were prescribed in the toxicology ward for only $14.5 \%$ of the poisoned patients. Considering that ceftriaxone has been the most commonly prescribed antibiotic, its use has to be based on clinical evidence based on the necessary indications according to scientifically substantiated sources.

\section{Author contributions}

Conception or design of the work: HM, MR, MA; Data collection: TY, FD, AB, PO; Data analysis and interpretation: HM, FD, PO, MA; Drafting and critical revision of the manuscript: $\mathrm{HM}, \mathrm{TY}, \mathrm{MR}, \mathrm{AB}, \mathrm{MA}$. All authors read and approved the final version of the manuscript.

\section{Conflict of interests}

None.

\section{Ethical declarations}

The study design was approved by the local Ethics Committee of Guilan University of Medical Sciences (Approval No. IR.GUMS.REC.1399.051).

\section{Financial support}

None.

\section{References}

1. Sepehri GR, Haj Akbari N, Mousavi A. Prescribing patterns of general practitioners in Kerman province of Iran, 2003. J Babol Univ Med Sci. 2005; 7(4):76-82.

2. Aminov RI. A brief history of the antibiotic era: lessons learned and challenges for the future. Front Microbiol. 2010; 1:134.

3. Abdi A, Faraji A, Dehghan F, Khatony A. Prevalence of selfmedication practice among health sciences students in Kermanshah, Iran. BMC Pharmacol Toxicol. 2018; 19(1):36.

4. Mosleh A, Khoshnevis Ansari S, Sorush M, Eghbalpor A, Babaeian S. Evaluation of the drug prescription status based on the WHO indices in pharmacies of health care centers affiliated to Tehran University of Medical Sciences. Med J Islam Repub Iran. 2011; 25(4):222-5.

5. Masters BR. Mandell, Douglas, and Bennett's. Principles and Practice of Infectious Diseases, (2015) Eds: John E. Bennett, Raphael Dolin, Martin J. Blaser. ISBN: 13-978-1-4557-4801-3, Elsevier Saunders. Springer; 2016.

6. Mera RM, Miller LA, Daniels JJ, Weil JG, White AR. Increasing prevalence of multidrug-resistant Streptococcus pneumoniae in the United States over a 10-year period: Alexander Project. Diagn Microbiol Infect Dis. 2005; 51(3):195-200.

7. Judge T, Pogue JM, Marchaim D, Ho K, Kamatam S, Parveen S, et al. Epidemiology of vancomycin-resistant enterococci with reduced susceptibility to daptomycin. Infect Control Hosp Epidemiol. 2012; 33(12):1250-4.

8. Hecker MT, Aron DC, Patel NP, Lehmann MK, Donskey CJ. Unnecessary use of antimicrobials in hospitalized patients: current patterns of misuse with an emphasis on the antianaerobic spectrum of activity. Arch Intern Med. 2003; 163(8):972-8.

9. Vogtländer NP, Van Kasteren ME, Natsch S, Kullberg BJ, Hekster YA, Van Der Meer JW. Improving the process of antibiotic therapy in daily practice: interventions to optimize timing, dosage adjustment to renal function, and switch therapy. Arch Intern Med. 2004; 164(11):1206-12.

10. Afrasiabian S, Koolani A, Barari M, Hajibagheri K, Moradi G, Mohsenpour B. Evaluation of the status of antibiotic prescription in patients admitted to a teaching hospital in west of Iran. Chronic Dis J. 2017; 5(1):1-7.

11. Liss RH, Batchelor FR. Economic evaluations of antibiotic use and resistance--a perspective: report of Task Force 6. Rev Infect Dis. 1987; 9 Suppl 3:S297-312.

12. Wojkowska-Mach J, Godman B, Glassman A, Kurdi A, Pilc A, Rozanska A, et al. Antibiotic consumption and antimicrobial resistance in Poland; findings and implications. Antimicrob Resist Infect Control. 2018; 7:136.

13. Amane H, Kop P. Prescription analysis to evaluate rational use of antimicrobials. Int J Pharmacol Biol Sci. 2011; 2(2):314-9.

14. Atif M, Sarwar MR, Azeem M, Umer D, Rauf A, Rasool A, et al. Assessment of WHO/INRUD core drug use indicators in two tertiary care hospitals of Bahawalpur, Punjab, Pakistan. J Pharm Policy Pract. 2016; 9:27.

15. Cosgrove SE, Carmeli Y. The impact of antimicrobial resistance on health and economic outcomes. Clin Infect Dis. 2003; 36(11):1433-7. 
16. Gholami A, Barati M, Vahdani M, Vahdani H, Karimi MA. Pattern of Empirical Antibiotic Administration in Emergency Department of an Educational Hospital in Tehran. Razi J Med Sci. 2011; 18(82):17-23.

17. Ebrahimzadeh MA, Ansari F, Ramezani A, Shokrzadeh M, Shabankhani B, Saeedi SS, et al. Utilization Pattern of Antibiotics in Different Wards of Sari Imam Khomeini Teaching Hospital. J Mazandaran Univ Med Sci. 2007; 17(61):166-9.
18. Robert J, Péan Y, Varon E, Bru J-P, Bedos J-P, Bertrand X, et al. Point prevalence survey of antibiotic use in French hospitals in 2009. J Antimicrob Chemother. 2012; 67(4):1020-6.

19. Radyowijati A, Haak H. Improving antibiotic use in low-income countries: an overview of evidence on determinants. Soc Sci Med. 2003; 57(4):733-44. 